\title{
Echando una mirada al tema del patrimonio
}

\section{Alexandra Arellano}

Puede decirse que el término "patrimonio" se refiere al legado colectivo de cada pueblo. La noción es atractiva, equívoca y debatida; refleja un legado común, pero es frecuentemente atribuida a las élites. El patrimonio nos devuelve a un pasado que puede ser nostálgico pero también conflictivo y ambiguo. Más aún, en lugar de ser un simple concepto referido al pasado, los científicos sociales, durante los últimos veinte años, han redefinido el patrimonio como un movimiento conservacionista que está convirtiéndose en condición de la última parte del Siglo XX. (McCrone 1994). De hecho, la noción de patrimonio se ha popularizado tanto en esta última década que al parecer está perdiendo su significado preciso. Los franceses hablan del patrimonio como la representación de un fenómeno de patrimonialización generalizada donde cualquier cosa bajo el sol es susceptible de ser protegido, recordado y guardado (Micoud, 1996). Para Pomian (1998), este "boom" del patrimonio refleja un interés renovado por la memoria colectiva, por las memorias nacionales, regionales y locales que hoy parecen ser más importantes que nunca. Adicionalmente, este movimiento también refleja un viraje hacia el pasado, por lo que es también visto como representante de una era en declive. Como lo pone Huyssen, hay una sensación de profundización de crisis frecuentemente articuladas en el reproche que nuestra cultura está enferma de manera terminal y con amne- sia (1995:1). La conservación, cualesquiera sean las dudas sobre la noción de patrimonio, es uno de los mayores movimientos estéticos y sociales de nuestro tiempo (Samuel, 1994: 25). De esta manera, el "boom" del patrimonio es visto como un fenómeno mundial de conservación o como una nueva "conciencia colectiva" que refleja un viraje hacia el pasado (Audrerie, Souchier and Vilar, 1998). La dimensión de este movimiento ha llegado a proporciones increíbles, donde el patrimonio se refiere a temas tan diversos como la protección de los modos tradicionales de preparar comida -como es el caso en Francia, con las normas estatales en cuanto al patrimonio gastronómico (Csergo, 1997) y los genes y la genética donde el genoma humano se ha convertido en materia de una dimensión colectiva de la humanidad, ya que UNESCO lo declaró "patrimonio común de la humanidad"(Tutton, 2001).

Primeramente, desde la perspectiva internacional, UNESCO estableció la Convención Internacional del Patrimonio en 1972 en la que las naciones participantes acordaron "proteger las propiedades culturales y naturales de valor universal sobresaliente contra la amenaza de daño en un mundo que se desarrolla rápidamente". De acuerdo con las definiciones de la Convención, "el patrimonio cultural" es un monumento, un grupo de edificios o un sitio de valor histórico, estético, arqueoló- 
gico, científico, etnológico o antropológico. "El patrimonio natural" designa características sobresalientes física, biológica y geológicamente; hábitats de plantas o especies en peligro de extinción y áreas de valor en los campos científicos o estéticos o desde el punto de vista de la conservación" (UNESCO.org).

La Convención Internacional del Patrimonio es frecuentemente tomada como propulsora del patrimonio como un movimiento del mundo. Sin duda, hasta la fecha, más de 150 países se han adherido a la Convención convirtiéndola en uno de los instrumentos legales internacionales más universales para la protección del patrimonio cultural y natural (UNESCO.org). Desde 1972, "cada uno de los Estados reconoce la obligación de asegurar la identificación, protección, conservación, embellecimiento y trasmisión para las futuras generaciones". (Audrerie, Souchier y Vilar, 1998). Por ello, en 1978, 12 sitios fueron declarados "Patrimonio Mundial" por el Comité de la lista de patrimonio mundial, mientras dos décadas más tarde (diciembre 2000), el número de sitios llegó a 690. De este número, 529 sitios son patrimonio "cultural" y 138 son patrimonio "natural" (UNESCO.org). Adicionalmente a estos sitios mundiales, cada uno de los países representados también ha contribuido con el movimiento de conservación al revisar su propio inventario de "edificaciones registradas" y promover el patrimonio y el pasado de diversas maneras. Más que el repentino incremento de los monumentos protegidos, la proliferación de museos de todo tipo o lo que Walsh (1992) Ilama "la nueva museología" también refleja el "retorno al pasado" que está convirtiendo a "los viejos países" como Gran Bretaña en museos gigantescos (Wright, 2985). Innovaciones en museología siguen tendencias como aquellas en las que los museos resultan "multifuncionales" ya que no solamente son lugares para la conservación y exhibición sino también como "lugares para estudio, para escuchar charlas, para discutir, para tener encuentros, para comer, tomar y comprar (Walsh, 1992; McCrone, 1995; MacDonald, 1996). Siguiendo lo tratado en la Convención de UNESCO, la primera parte de este artículo evalúa la administración del patrimonio por el Estado en Francia y los discursos autenticando recuerdos nacionales.

En segundo lugar, desde otra perspectiva mundial, el movimiento del patrimonio y la "patrimonialización" es afectada por el proceso de glo- balización, sobre todo en lo que se refiera al impresionante desarrollo de la industria del turismo, donde un número significativo de los 698 millones de pasajeros internacionales cada año (worldtourism.org) está asociado con el turismo de patrimonio. En efecto, como Graham (1994) subraya, la visita de sitios patrimoniales es la actividad más popular para los turistas extranjeros. La reorganización de las infraestructuras del turismo, la reestructuración de las ciudades para ser miradas (ver Urry, 2001; Judd y Fainstein, 1999), la proliferación de los sitios de atracción y los parques temáticos (ver Dicks, 2000; Macdonald, 1997), son todos los asuntos de interés interconectados con el patrimonio. Particularmente en Gran Bretaña, todos estos asuntos están sujetos a intensos debates que discuten y critican la mercantilización de la cultura y de la industria del patrimonio. De hecho, visto desde este álgido punto de vista, el mundo capitalista profundo estaría mercantilizando el pasado allí donde el movimiento del patrimonio fuera impulsado por una demanda turística. Además, este hecho se conecta con las movilidades crecientes (ver Urry, 2000) en un mundo en el cual el tiempo y la distancia están comprimidas (Harvey, 1990) donde la mercantilización del patrimonio puede ser vista como una oferta económica para una demanda que busca referencias de estabilidad e identidad definidas. De acuerdo con esta perspectiva de la industria del patrimonio, en la segunda sección abordo la crítica británica sobre la mercantilización de la cultura.

Como podemos ver, la literatura sobre el patrimonio es muy profusa y puede ser discutida desde diversas perspectivas. Mi objetivo, en este caso, es el de presentar una vista panorámica de los diferentes debates y el de comparar los puntos defendidos por las diversas representaciones y administraciones del patrimonio. Más específicamente, sabiendo que el debate británico levanta preguntas que son por lo general inexistentes en otros debates sobre el patrimonio -como el caso de Francia, Canadá y España, por ejemplo, quiero subrayar estas diferencias discutiendo sus respectivas contribuciones al debate. En una primera sección, abordo el patrimonio como un tema muy vinculado a la administración del Estado como en el caso de Francia. Luego reseño de manera crítica algunos aspectos del debate británico y la crítica de la mercantilización del patrimonio. Más que el discurso administrativo de manejar el patrimonio y más que criticar su mercantilización, en la literatura general 
de Gran Bretaña, Francia, y otros países, es también posible pensar en el patrimonio como una condición del Siglo XX. En la tercera sección, discuto sobre el patrimonio y el tiempo.

\section{I.-EI patrimonio y el Estado}

Francia es reconocida como precursora del movimiento patrimonial y uno de los primeros países que tomaron conciencia de sus legados en nombre del interés común. Este sentido de comunidad y de propiedades colectivas esta intimamente relacionado con la idea de nación y nacionalismo que se originó durante la Revolución Francesa. Desde esta perspectiva, el patrimonio se ha referido a la transformación del estatus de objetos privados en antigüedades nacionales. Después de la Revolución, uno de los primeros actos jurídicos fue el de transferir las posesiones clericales para ponerlos a disposición de la nación. El patrimonio es Francia, es la memoria colectiva de la nación, la identidad, el espejo de la gente. También hay un fuerte sentido de responsabilidad nacional y solidaridad inscrita en un Estado de una tradición fuertemente intervensionista. Por cierto, en Francia la cultura y el patrimonio son asuntos nacionales donde el Estado tiene el encargo legítimo de administrar. Durante los dos siglos posteriores a la Revolución, el país ha desarrollado un complejo arsenal jurídico para proteger y difundir su patrimonio. En 1964, el ministro André Malraux programó el Inventario general de monumentos y de riqueza artística de Francia que promovió casi una nueva revolución de conciencia patrimonial. En 1980 se decretó el año del patrimonio. Además, en 1984 se creó el día nacional del patrimonio y desde entonces, cada año, millones de franceses en el mes de septiembre invaden las legaciones históricas y los templos nacionales para celebrar los tesoros arquitectónicos y artísticos del país. Paralelamente se dio la creación de toda clase de museos: El patrimonio ahora está relacionado al fervor nacional y su defensa se ha convertido en religión. Para los franceses no hay duda que el patrimonio es tema de la nación, de la gente. (Grange, 1997:13)

Desde 1964 y el Inventario de Malraux, el movimiento patrimonial en Francia ha tomado una importancia grande en las prioridades del Estado y en la conciencia colectiva. Para los franceses el patrimonio es visto como un modo de equilibrar los incesantes cambios del mundo moderno, el sentimiento de desarrollo, la aceleración de la historia, la explosión del mundo moderno y la banalización de criterios sociales son todos los síntomas que requieren nuevos sistemas permanentes e identificables. Por ello, en este caso, el papel del Estado es esencial para promover, administrar y difundir el arte y la cultura patrimoniales en general. Como argumentó Renan, para captar el sedimento histórico de nuestras instituciones culturales y científicas tenemos que recordar la idea defendida por la característica más profunda del espíritu francés, que interpreta a las ciencias, las letras y el arte como asuntos de Estado; algo que cada nación produce en armonía y que la Patria tiene la tarea de incitar, promover y premiar (citado en GenetDelacroix, 1997: 147-148).

De este modo, cuando un nuevo signo del pasado o símbolo cultural es visto como representante de lo francés y vale la pena aprovecharlo y guardarlo, una comisión especial de la Dirección de Patrimonio del Ministerio de la Cultura reconoce este edificio o paisaje como un sitio patrimonial, el cual es, a continuación, oficializado como patrimonio nacional y como una fuente de identidad renovada y permanente; sea este nacional, regional o local.

Tradicionalmente, importantes edificios que representaban un período o que tenían un significado específico y un sentido fueron el objeto principal del patrimonio y la patrimonialización. Luego, un edificio principal, un templo, una catedral, un palacio, un castillo, una cabaña o monumento, grupos de monumentos, ciudades enteras y pueblos se han convertido, hoy, en objetos de conservación. Además, la naturaleza, los parques naturales y, más recientemente, usos y costumbres han sido declarados patrimonio cultural. En este caso, en Francia, hasta los modos específicos de preparar comida son guardados. En ese sentido la constitución de la especialidad gastronómica en un objeto patrimonial es un interesante ejemplo francés en el cual se describe el proceso de patrimonialización por el Estado, por la gente (ver Csergo, 1997). Por cierto, lo que se ha institucionalizado, legislado y transformado en interesantes objetos mercantiles para los empresarios es mucho más que edificios, paisajes o modos tradicionales de preparación de comida. Desde 1989, secciones institucionales han participado en la creación de una política de patrimonio culinario; primero, la Dirección de Museos de Francia y la Dirección de Patrimonio a través de trabajos encargados por la Misión del Patrimonio Etnológi$\mathrm{co}$, donde las nuevas políticas culturales han sido organizadas por el Consejo Nacional de Arte Culi- 
nario que está a cargo de administrar el interés nacional en gastronomía y fijan las orientaciones de una política conservadora (Ibid: 184). Así, los procedimientos de apropiación de los inventarios administrativos y la transferencia del patrimonio colectivo en una soberanía nacional son operaciones de restitución por la creación de políticas basadas en dos orientaciones. Primero, se emplea un enfoque histórico y etnográfico legítimo para evaluar la fuerza vinculante del producto con la localidad y a la autenticidad de su memoria. En otras palabras, los historiadores y antropólogos son "expertos en autenticidad" que representan al Estado y a la $\mathrm{Na}$ ción, instancias que institucionalizan la versión correcta de patrimonio. Estos comités sugieren orientaciones para una política de retroalimentación cualitativa, donde el reconocimiento y el reclamo convierten al patrimonio en un importante hito económico y social.

Segundo, este "sitio patrimonial" sigue su curso hacia una "inscripción de gusto" y conocimiento a través de la creación de una política de educación nacional. De hecho, luego de ser transformado en patrimonio "nacional", se suma una gastronomía específica - es decir, "el secreto de un método complejo de alimentación que va más allá de lo requerido por la necesidad",- a los programas de educación pública. Este procedimiento es incluido como nuevo aspecto de la educación de la vista y del oído a través del programa de "el despertar del gusto" destinado a los niños de escuelas primarias (Ibid.: 184). Como sostiene Csergo, los orígenes de la gastronomía se encuentran en el Siglo XVIII, Siglo que fue testigo de la multiplicación de restaurantes y el inicio de una literatura crítica de la gastronomía.

Es a través de la formulación de un discurso y del nacimiento de un juicio crítico que se puede hablar de la experiencia sensorial. Este juicio crítico sensorial tiene su objeto en la calificación del gusto y en el establecimiento de la universalidad de criterios sobre la "estética gustatoria". Estos criterios fueron el medio por el que el trabajo culinario y más específicamente la especialidad de la comida local se convirtieron en objeto de arte "tal como lo es un edificio histórico". Por lo cual estos objetos de arte culinarios -al igual que lo que ocurre con cualquier sitio histórico- se convierten en objeto de estudio aún antes de ser objetos de la historia a través de la función de la memoria y de convertirse en objeto de resguardo. (Ibid.: 185)
Csergo identificó tres fases en el desarrollo del patrimonio gastronómico en Francia, donde la tercera fase, la del "inicio del siglo XX," está relacionada con el desarrollo del "turismo en automóvil". Es un hecho que después de la primera guerra, el descubrimiento de nuevas rutas y regiones favorecieron la constitución de "estereotipos culinarios" que fueron también reforzados por la creación de las Guías Michelin y la Guía Bleue en 1910. El turismo es esencial para el movimiento de "patrimonialización" de las últimas décadas, y estas prácticas turísticas son reconocidas como culturales y económicas, que ayudan a desarrollar la "memoria culinaria". De este modo, el turismo es visto como una herramienta de reapropiación de las gastronomías tradicionales. En algunas regiones de Francia la gente de la localidad inclusive ha reclamado la reforma local en favor del desarrollo y la salvaguarda de la cocina regional, las especialidades de la memoria culinaria y la autenticidad del "savoir faire". Dicho de otro modo, una especialidad culinaria está también relacionada con la regeneración económica y la valoración turística de la localidad. La patrimonialización de una especialidad culinaria está definitivamente relacionada con diferentes objetivos económicos como:

La valorización turística de un sitio histórico y su contribución a la tradición como recurso de la localidad: mantiene la organización social rural que está tan comprometida y el equilibrio de la balanza comercial del país. En un proyecto cultural llevado a cabo por el poder público para la preservación de una memoria culinaria que integre, por naturaleza propia, la innovación gastronómica, constituiría un lugar patrimonial al mismo nivel que un edificio histórico, que contiene en sí un futuro positivo económico y social. (Ibid.: 193).

En pocas palabras, la constitución de una tradición colectiva, de un edificio, de una práctica o de un paraje en un objeto de patrimonio nacional es materia de re-simbolización y la instauración de un nuevo significado que transforma el objeto en "recurso". Como explicó Micoud (1977), cuando algo es instaurado como recurso para ser administrado patrimonialmente (bajo la rubrica del patrimonio oficial), es "ipso facto" instituido como "heredado", "unido" e "irremplazable". Y de alli en adelante el beneficiario compuesto por distintas personas es calificado como heredero solidario. El trabajo de "patrimonialización" es un trabajo social en el que se confiere dignidad y autoridad a miles de diversos 
actores y consiste en producir "frenesi" social, conocimiento y textos de regulación, objetos empíricamente observables de un conocimiento etno-sociológico (Micoud, 1977: 117).

Más que citar las funciones administrativas, el patrimonio se ha convertido en un tema mayor entre los científicos sociales. La producción francesa del discurso de patrimonio es significativo; congresos, reuniones anuales, escuelas de patrimonio, seminarios, programas especiales, comisiones de investigación, y todo tipo de organizaciones están relacionadas con el patrimonio. El masivo trabajo interdisciplinario colectivo titulado Les Lieux de Mémoire, dirigido por Pierre Nora refleja la variedad de disciplinas involucradas en el estudio del patrimonio que es visto como resultado de la "era de conmemoración". (Nora, 1997)

\section{II.-El debate británico}

Hay algo fascinante en la literatura británica sobre el patrimonio. Es un debate, es criticado, y no se relaciona, necesariamente, con el Estado. La crítica ha tomado tal dimensión que no sólo involucra los cambios museológicos en las discusiones (mientras el país se convertía en un museo gigante), sino que también está presente en la política y en la "teoría de la conspiración" (el patrimonio es visto como un símbolo de decadencia nacional, una trama, una estrategia política que pone el conocimiento al servicio del poder y de las élites), está presente en ciencia y la vulgarización de la Historia (el desvío del conocimiento hacia un objeto de deseo, entretenimiento), está presente en el capitalismo y la mercantilización de la cultura y el pasado (turismo como "envoltura" y "disneylandización" del pasado), o también en la autenticidad y patrimonio como pastiche, (simulacros o espectáculo en la hiper-realidad). De manera similar, el movimiento de patrimonio es visto como un cambio en la temporalidad reflejando a una sociedad en declive o una cultura amnésica que tiene que mirar atrás, al pasado, para encontrar confort en el presente.

Todas estas dimensiones están vinculadas unas a otras en un modo $u$ otro $y$ todas se fundamentan en una crítica del patrimonio. Como hemos visto, la literatura sobre el patrimonio en Francia tiene posiciones totalmente diferentes, donde el patrimonio toma un sentido "armonioso" de la memoria colectiva local o nacional, que está estrechamente conectada con temas de identidad y comunidad. Sin embargo, los asuntos debatidos en la crítica británica sobre el patrimonio existen pero en la sofisticada forma de la "alta teoría contracultural" desarrollada por Foucault con asuntos de poder y conocimiento y Bourdieu con la cultura museo (Samuel 1994: 264). La organización y administración del patrimonio en estos dos países tienen variaciones y tradiciones que podrían explicar algunas diferencias en los discursos relacionados con ellos. Como McCrone argumenta,

En la Francia republicana los ímpetus para cuidar el patrimonio provienen principalmente del Estado, y el rol de las organizaciones voluntarias es pequeño. Lo que se trasmite es un fuerte sentimiento de herencia nacional o patrimonio, muy vinculado con la imaginería rural y cultura campesina que tiene una continua importancia política en la República Francesa. En la Gran Bretaña monarquista, al otro lado del Canal, el rol del Estado es relativamente pequeño comparado con aquel de las organizaciones voluntarias como el National Trust de Escocia que tiene un "ethos" orgánico e incluso aristocrático. (1995: 13).

De hecho, las instituciones de las que depende el mantenimiento de la cultura tienen un rol significativo en la producción del discurso de patrimonio (Hewison, 1987: 10). A continuación presentaré un panorama resumido de las principales corrientes de la crítica británica:

\section{II.1. La teoría de la conspiración}

Los precursores de la crítica británica del patrimonio son Robert Hewison (1987) con sus trabajos The Heritage Industry, Great Britain in a Climate of Decline y Patrick Wright (1985) con Living in an Old Country. Wright atacó principalmente al movimiento de patrimonio como representante de "la nostalgia aristocrática y reaccionaria sobre las tendencias niveladora de Seguridad del Estado". De hecho, según la teoría de la conspiración, una trama o proyecto y estrategias seleccionan el proceso de "memoria histórica". Como lo expica Samuel, "es una pugna de hegemonía, un modo de usar el conocimiento en servicio del poder. Trae al recuerdo el asunto de la identidad nacional en un momento en el que está acosada por incertidumbres provenientes de los más diversos sectores. Es una manera de compensación por el co- 
lapso del poder británico (1994: 243). Para Hewison, el movimiento conservacionista en Gran Bretaña hubiera sido promovido por el Gobierno Thatcher propagando la idea de nación con "cultura y tradición" para legitimar y dar referencia de una identidad o un sentido de comunidad a la población en crisis. Realmente, este argumento se refiere al intento, por parte del gobierno, de disolver este clima de crisis explotando el potencial económico de la cultura (1987: 1). De este modo, el programa del Estado británico desarrollado durante los años 80, movilizó la identidad nacional para transformar la sociedad. "Patrimonio bajo la forma de un "pasado recordado" de hechos y procesos simbolizados a través de monumentos y artefactos fue movilizado por el Estado para ocasionar el cambio social y económico" (Hewison, 1997). En otras palabras, el desarrollo del patrimonio diseminado por esta idea política de cambio económico es vista como un mecanismo de imposición de nostalgia por un pasado nacional "que nunca fue". Samuel explica que es plausible pensar que en el contexto político en el que el patrimonio comenzó a ser atacado, la crítica cabía en la expresión de la ideología dominante. "Los conservadores estaban adelante luego de tres victorias en las elecciones generales, y la guerra de las Malvinas" parece señalar el punto de retorno de una cándida ignorancia y empobrecimiento inglés, en el que los sueños de supremacias desaparecidas sirvieron como consolación por el colapso del poder inglés (1994:290). En otras palabras, en Inglaterra, el patrimonio puede ser visto como una herramienta usada por la nación donde el nacionalismo es una ideología al servicio de los intereses nacionales elitistas. Como explica Urry, en Inglaterra las casas y propiedades de la mayoría de la clase agraria basada en tierras que viven en el sur de Inglaterra han sido aquellos que han sido "guardados para la nación" por el National Trust y otras organizaciones conservacionistas. Son estas casas, propiedades y formas resultantes de la vida de la clase alta las que han sido consideradas como parte del patrimonio nacional y para definir la "esencia inglesa".

\section{II.2. El patrimonio como mercancía}

¿Qué viene antes, el patrimonio o el turismo? Es que la reestructuración de la economía del mundo y la explosión del turismo masivo internacional provocaron el aumento y la conciencia del patri- monio para "la mirada del turista" o es más bien el movimiento conservador el que, interesado en los pasados colectivos, motivó el tratamiento del patrimonio como una mercancía. Para McCrone, "el auge del patrimonio ha sido puesto en marcha por propulsores comerciales, políticos e intelectuales, que le han dado, en la última parte del Siglo XX, un predominio poco usual. (1995:12). Una cosa es segura, las dos prácticas que corresponden a estas nociones son "primas hermanas" ya que-según dicen-el patrimonio, la cultura y el pasado se han vuelto pronunciadamente capitalistas. "El capital no ha mostrado demasiado interés por la Historia; más bien ha preferido destruir cualquier herencia que pudiera tomar. Ahora, el capital también se ocupa de organizar el pasado. Hay una profusión extraordinaria de estrategias de alta tecnología para "recuperar" el pasado en los museos, parques temáticos, esquemas de restauración, etc., y para representarlo o más precisa y profanamente, venderlo a los británicos y a los visitantes de la nación. (Schwarz, 1991 citado por Samuel, 1994:253).

Más aún, también se dice que la cultura no ha sido transformada en una simple mercancía pero se está convirtiendo en la mayor mercancía ya que define una "característica del post modernismo (McCrone, 1995:34) La cultura ha sido reconfigurada en términos de una demanda económica que se relaciona con diversas nuevas industrias con sus respectivas prácticas. En una sociedad consumista donde "la desindustrialización y el postfordismo han reemplazado la economía de manufactura por la economía de servicio (Ver Lash y Urry, 1994), los empresarios han reconocido el potencial económico del patrimonio. Una manifestación de esta economía consiste en la reestructuración de ciudades y la explotación de los "recursos" culturales. McCrone argumenta que:

En muchas ciudades británicas, se habla de "la opción patrimonial" como el medio de regeneración y la "economia cultural" como el modo de acceder al status post industrial urbano. Estas industrias culturales incluyen a las tradicionales como museos y catedrales, pero también incluyen a galerias de arte, teatros, orquestas, arte comunitario, franquicias televisivas y el espectáculo. (McCrone, 1995:18)

En Gran Bretaña, el caso de Glasgow es uno de los proyectos de regeneración más exito- 
sos. En los años 70, Glasgow tenía una reputación de "militancia industrial y política, de sectarismo religioso y de violencia extremista y urbana (Ibid.: 38). Luego de declararse en urgente necesidad de regeneración económica, la ciudad se convirtió, en 1990, "la ciudad europea de la cultura" y el modelo económico de desarrollo para las ciudades y los países vecinos. En 1992, Glasgow llegó a ser la tercera ciudad más visitada en Gran Bretaña después de Londres y Edimburgo con 420,000 visitantes de fuera y un incremento total del 90 por ciento. Generalmente, los fondos de desarrollo vienen de cuerpos patrimoniales como el National Trust, el Patrimonio inglés o el National Trust de Escocia; los fondos públicos del gobierno central; y también de empresas locales y centrales. El éxito de la reestructuración en Glasgow no está exenta de críticas. Se dice que la regeneración de Glasgow se basó en el turismo y el patrimonio pero que este patrimonio no coincide bien con el de su historia real. Esto ayuda a señalar que en la política cultural de los años 90 esto no se requería 'Glasgow ha actuado como un empresario en la realización de la traducción de una estrategia norteamericana 'de desarrollo cultural por esfuerzo propio' como medio de regeneración económica" (Ibid.: 39)

Hay desilusión con respecto a la industria artística que empobrece la calidad y creatividad de las artes en general. Se dice que el arte tratado como mercancía va de acuerdo con la demanda y la meta de hacerse financieramente rentable, allí donde el arte es valorado sólo por la cantidad de dinero que genera. "La disneyificación o McDisneyización de la cultura o el patrimonio trata el pasado y la historia como gafas para el entretenimiento (Ver Ritzer y Liska, 1997; Debord, 1996). Al referirse a la industria cinematográfica, la crítica de John Malkovic responsabiliza a la industria cinematográfica de derribar todo lo que se le pone en el camino, "como un anciano árbol muerto que cae desde una gran altura para humedecer al torpe y verde pasto". (Malkovich, 2001: 2). Mientras discutía la industria justifica la producción con la demanda ya que:

El público es una parte importante de la industria del cine, consumidor empedernido de lo peor que tienen para mostrar las peliculas. Quizá uno puede decir que el público consigue el tipo de películas que merece, la clase de arte que merece, el tipo de políticos que merece y la clase de cultura que merece (Ibid: 2).

El arte se convirtió en una mercancía marcando una diferencia con la venta que sofoca la creatividad. Y lo único que le queda a los artistas "reales" -al contrario de los empresarios- es contentarse con el apoyo de un buen trabajo por su propio bien, y por la aplicación de la noción de estar asociados con un buen trabajo y con lo que se gana personalmente.

Estos críticos parecen hablar de arte, cultura, patrimonio e historia como si tuvieran la misma definición. ¿Es que el arte, la cultura y hasta el patrimonio pertenecen necesariamente al pasado? ¿Y qué tipo de pasado? ¿Por qué se dice en Gran Bretaña que los objetos patrimoniales requieren ser "pasados" para ser considerados "auténticos" y ser aceptables? McCrone ilustra esta idea: En una charla en Aberdeen, en una oportunidad preguntamos por qué era que pensábamos que había sido tan difícil establecer un centro de patrimonio en la ciudad dedicada al aceite del Mar del Norte. Nuestra respuesta fue que esto no ocurriría hasta que y a menos que los aceites del Mar del Norte no fueran más un fenómeno económico. Si Escocia es rico en patrimonio, entonces puede deberse a que tiene un pasado pero no un presente o un futuro (1995:6).

Una importante dimensión de la crítica de Hewison se basa en el modo en el que el pasado es tratado y percibido. Como resultado de la patrimonialización del nostálgico pasado como "mejor que el presente", el autor se preocupa por aspectos de renovación y creatividad. Bien visto, este "mejor" pasado aliena al sujeto que quiere vivir en el pasado. La industria de patrimonio no está interesada en el arte como proceso de hechura y renovación sino en los trabajos de arte ya logrados, trabajos que puedan ser consumidos como símbolos de la cultura general del patrimonio que las instituciones mantienen. La cultura es el trabajo de una sociedad en su conjunto, pero el arte es hecho por individuos y es a estos individuos a los que debemos acudir buscando percepciones frescas del presente y nuevas aproximaciones al legado del pasado (Hewison, 1987: 144-45).

Tal como fue sugerido páginas arriba, el caso de Francia y algunos otros países donde el patrimonio es manejado de cerca por el Estado se dan diferentes discursos en los que aparentemente no se 
critica la mezcla de cultura y comercio. El desarrollo del patrimonio dentro de políticas gubernamentales demuestra otros modos de administrar y otros discursos sobre el patrimonio. Una de las principales diferencias de la aproximación al patrimonio está relacionada con una relación compatible y armoniosa entre el patrimonio y el desarrollo económico. En Québec por ejemplo, el discurso del patrimonio esta sólo relacionado con los estudios de identidad y cultura como modo dinámico de regenerar las localidades para los habitantes " $y$ " para el turismo (Fortín, 1995). El discurso general es frecuentemente relacionado con las políticas culturales como "productoras" de imágenes.

La preservación y conservación del patrimonio son responsabilidades del gobierno que toma parte activa en el desarrollo de una vida cultural. EI patrimonio toma el significado de algo para usar para crear referencias de identidad, para dar un alma al lugar y un sentido de comunidad. Este predominio de la idea de una identidad relacionada cercanamente con el patrimonio y el pasado explica, en parte, esta dinámica del patrimonio como reflejo de personas distintas. Pero una de las características de este patrimonio como espejo de la comunidad es el hecho que no se ve estrictamente como algo venido del pasado que tiene la connotación de "terminado" y "muerto" o algo para recordar o sobre lo cual sentirse nostálgico. Como Bassand argumenta, "Hoy la identidad no puede fundarse exclusivamente en la búsqueda de nuestras raíces y tradiciones. Esta tendencia traería consigo los gérmenes de la asfixia. Consecuentemente, la identidad tiene sentido sólo si se asocia con las disimilitudes del presente y del futuro". (Bassand, 1991:11).

Si seguimos esta idea, puede decirse que el patrimonio es visto como "dinámico" y "creativo". En otras palabras, para estos autores, es obvio que el patrimonio cultural, histórico y natural no está referido únicamente a los pasados, diferentes o separados del presente y del futuro, sino a los pasados que están vivos, que influencian el presente y que deben ser celebrados y protegidos.

El ser moderno es considerado como "histórico" en el sentido que va cambiando continuamente y va perpetuamente construyendo una identidad. Lo mismo ocurre con las identidades colectivas. De esta manera, los desarrollistas son concientes de estar "creando identidad", casi "in- ventando" identidades. El patrimonio es concientemente administrado por los gobiernos locales y por la gente. El pasado tiene que inspirar un proceso de creatividad orientado hacia un proyecto dinámico de regeneración o vivificación.

\section{II.3. La nueva museología}

Para Hewison, el sólo hecho que el número de museos haya incrementado desde 1960 es un síntoma de declive. No sólo las grandes ciudades sino también las localidades más pequeñas están experimentando una regeneración local al comercializar el patrimonio. Los años 80 en Gran Bretaña fueron testigos del nacimiento de los nuevos tipos de museos o centros patrimoniales como el Lewis Merthyr Colliery que fue transformado en el Parque Patrimonial Rhondda en Cardiff, el centro patrimonial de Puerto Wigan en Lancashire, el museo al aire libre Beamish cerca de New Castle o el Muelle Albert en Liverpool. Numerosos de estos nuevos tipos de museos son criticados por estar destinados a actividades comerciales y de entretenimiento en lugar de dedicarse a la educación e historia del pasado y del patrimonio. La crítica acusa severamente a la capital de estar traficando con la historia, la cultura y la autenticidad. El pasado está siendo rematado y esta simple idea es suficiente para dar la idea de una sociedad decadente. La transformación de los museos en "casas-prisiones de artefactos, 'souvenires', y tiendas de regalos es una forma de mercantilizar el pasado". (Samuel, 1994: 263). Tal como Hewison explica, en 1979 los museos fueron forzados a entrar al mercado por el Estado. En consecuencia, el nuevo tipo de museos, centros patrimoniales y parques temáticos han sido desarrollados como empresas y tuvieron una mayor libertad que aquellos dirigidos por el Estado. "Los años 80 se han caracterizado como el período de una profunda desconexión del Estado británico, ante la insistencia del gobierno del hecho que el mercado constituiría, de allí en adelante, la clave de la relación social entre el museo y el visitante". (Bromwich, 1997). De modo que este aspecto fundamental relacionado al mercado organizó el patrimonio del mismo modo que cualquier otro producto comercial (Hewison, 87: 1).

Beamish es un buen ejemplo de un "museo al aire libre" sin ninguna vitrina de exposición y muy pocas placas explicativas o pizarras informativas. Dentro del pueblo reconstruido, el personal 
es entrenado para hablar a los visitantes y para responder a sus preguntas sobre "cómo eran o vivían sus antepasados". Estas preguntas son vistas por los "puristas" como síntomas de una sociedad decadente, nostálgica sobre un pasado y formas de ser "terminados". De este modo es como Hewison reclama que Gran Bretaña se está convirtiendo en "un gran museo al aire libre" (1987: 88). A pesar de lo que dicen los críticos, en 1986 se seleccionó al Museo Beamish como el museo del año, mientras en 1987 el reconocimiento fue dado al Museo Europeo. Peter Lewis, director de Beamish, el museo al Aire Libre del norte de Inglaterra, escribió lo siguiente:

"Algunos puristas, abogados de las técnicas convencionales museísticas, han supuesto que la popularidad no es consistente con la erudición. Esto nunca ha sido así. Beamish continúa siendo en primer lugar un museo con un propósito educativo serio, pero nunca se ha tomado a si mismo demasiado en serio. Siempre ha reconocido que la recreación y el entretenimiento son partes importantes del proceso de aprendizaje. Los museos son demasiado importantes para ser dejados a los curadores y a los historiadores académicos". (Lewis, 1991).

En efecto, el hecho que los museos y la cultura estuvieran integrados al mercado, debido a su "mercantilización", trajo consigo una serie de cambios en las técnicas de exhibición y los procesos de aprendizaje. Estas nuevas técnicas incorporaron nuevos métodos instando a los visitantes para que sean más activos allí donde se den los nuevos métodos de aprendizaje o de "aprender haciendo", allí donde los acercamientos a la educación busquen llegar a los diferentes "sentidos" (ver Samuel 1994; Bromwich, 1997).

Macdonald (1997), estudió Aros: El relato de Skye, un centro patrimonial en la isla escocesa de Skye que abrió sus puertas en 1993. Este estudio de caso es un interesante ejemplo que muestra cómo están interconectados el comercio y la cultura en un sitio patrimonial de Gran Bretaña. Al estudiar a Aros, su objetivo fue el dilucidar "hasta qué punto el centro es responsable de la mercantilización de la cultura y la historia" (1997: 155). Este centro patrimonial es uno de estos típicos "nuevos" tipos de museos, construidos siguiendo los méto- dos técnicos del estudio específico de un "modelo patrimonial comercial" (1997). Este modelo de museo es diseñado como cualquier otro negocio; existen "empresas" previamente establecidas que se especializan en la consultoría de quien quiera "iniciar" un centro patrimonial. Es el caso de "las compañías basadas en el patrimonio de Edimburgo que surtieron de maniquíes, vestidos de época, paneles gráficos y técnicas audiovisuales y que asesoraron en temas como el cómo escribir una historia cautivadora, el cómo exhibir los artefactos de la mejor manera, y el cómo tentar a los visitantes para que entren a la exhibición y la tienda de regalos". (1997: 157). De hecho, estos tipos de museos no confían en las colecciones de artefactos "antiguos" como lo hace el museo tradicional sino que reconstruyen escenas a partir de una cuidadosa selección de objetos. Para los creadores de Aros, los objetos "antiguos" y su sentido aurático de "haber estado alli" en el pasado o su proveniencia no son condiciones suficientemente determinantes: "Lo que importa para ellos es que los objetos representen la imagen correcta, pues la autenticidad en Aros no está en el aura de los artefactos sino en la historia que se cuenta" (ibid: 170). Pero, ¿es que la historia no fue modificada para ser atractiva y entretenida para las compañías basadas en el patrimonio de Edimburgo? ¿Qué tipo de historia del pueblo es la que se cuenta en el centro patrimonial? Macdonald indica que los autores -sin ser obsesivos con la idea de autenticidad- eligieron presentar "una historia verdadera y honesta".

De acuerdo con la historia y el modo en que fue construida por los creadores, se puede sugerir que la relación entre patrimonio y comercio implica ideas muy debatidas. Por cierto, el asunto que se pregunta el autor no es si la gente de Isla estuvo de acuerdo con esta versión de la historia o si ella corresponde al modo particular de representación de sí mismos.

Además, ella tampoco insiste en cuanto al tema de la clase de autoridad que los autores adquieren por ser los "creadores y productores" de la versión que están "imponiendo" a la Isla. Más bien lo que hace es preguntarse cómo es que esta historia -que compite con historias alternativas más establecidas- se vuelve obligatoria y adquiere autoridad? Ante esta pregunta Macdonald objeta las tecnologías de exposición basadas en "los hechos", "el realismo", "lo visual" y los diversos modos sensoriales. Estas técnicas son vistas como "modos 
alternativos de autenticación o visiones alternativas de las identidades Skye o Gaelica" (Ibid.: 172). $Y$ contrariamente a los museos del lugar "ya establecidos", Aros está articulando identidades cambiantes y movibles que corresponden mejor al tiempo presente del Skye moderno. En otras palabras, Aros compite con otros sitios patrimoniales que también construyen sus propias versiones de cultura e identidad.

Como arguye un "creador-productor, la historia que contamos es muy diferente a lo que se cuenta en otros lugares de Skye, especialmente en Dunvegan y Clan Donald. No estoy criticando lo que ellos hacen sino que es una historia completamente diferente, contada desde otro punto de vista. Pero, también somos cuidadosos de no pisarles los callos" (1996: 161). Más aún, aún si este asunto no estuviera particularmente desarrollado en la investigación, Macdonald menciona algunas de las percepciones locales del centro patrimonial de Aros y "la versión de la historia de la gente lugareña". A muchos de ellos les es claro que la exposición está dirigida a turistas; "en otras palabras, que no está dirigida a los lugareños"; esto es una debilidad desfavorable; es una aventura comercial, todas son aventuras comerciales. "Son para turistas, no son de nuestro gusto". ¿Es este el clima general del declive criticado por Hewison?" En esta isla el pasado parece tener una identidad omnipresente en muchas diferentes expresiones pero ies que podemos encontrar esfuerzos colectivos, solidaridad o identidades compartidas? Diversos intentos de mostrar el pasado parecen estar reclamando su propia versión de un pasado que represente a muchos diferentes grupos dentro de una cultura que supuestamente debería tener las mismas raíces. ¿En qué condiciones serán contemplados el presente y el futuro? Para el autor esta joven gente de la localidad están haciéndose la vida de su proveniencia gaelica, "una experiencia histórica local singular". Como concluye el autor, "el centro patrimonial y el turismo cultural en general pueden ser un modo de contar la historia de las gentes y de colaborar con el trabajo de asegurarse que estas historias sean escuchadas."

\section{III.-El patrimonio y el tiempo}

De acuerdo con Micoud (1996), el concepto contemporáneo de patrimonio se refiere a un sentido de pasado diferente al presentado por la histo- ria, la conservación y los museos. Estos últimos conceptos usualmente representan el pasado que sigue la idea modernista del progreso donde el pasado es visto como algo "terminado". McCrone (1995) expresa esta idea como "doscientos años atrás, la idea de progreso fue central al proyecto modernista de mejoramiento cultural, económico y social. El pasado fue un punto fijo desde el cual medir ese progreso" (1994). En ese sentido, esta idea conlleva una connotación que fija el pasado como algo "muerto", como algo que simplemente tiene que ser preservado y recordado "como fue". El futuro es visto como mejoramiento del pasado y del presente. Más aún, De Certeau (1978) indicó que es desde la construcción de la institución de la historia como ciencia que el pasado se convirtió en algo "terminado" y "muerto". Desde el momento en que el pasado se transforma en un "objeto de conocimiento", bajo el criterio de esta "verdad objetiva" y está sujeta a debates y controversias, la relación con el pasado resultante se instituye como "fija e inalterable" (Micoud, 1996: 115). Por cierto, el museo "siempre ha sido atacado como síntoma de osificación cultural por todos los que hablan en nombre de la vida y renovación culturales contra el peso muerto del pasado (Huyssen, 1995: 13).

El modo francés de percibir el manejo del pasado ve al patrimonio como representante de una nueva relación con el pasado que intenta revivir como "equilibrando" la temporalidad. Para Micoud, el Patrimonio representa un nuevo modo de representar el pasado siguiendo los últimos cambios de las sociedades contemporáneas donde las nuevas concepciones de tiempo y espacio no se apoyan simplemente en modos de representación linear y progresiva. En otras palabras, la idea de patrimonio sería una "resistencia" a la "compresión tiempo-espacio" de Harvey (1989), que implica cambios en tiempo y distancia que confunden los horizontes sociales. Más aún, esto también está conectado con lo que Urry llama el "tiempo instantáneo" de la post-modernidad, que se conecta con la falta de confianza en el futuro y conduce a una "increíble atracción del pasado". (Lash y Urry 1994: 246). Desde una primera perspectiva, el patrimonio sería el resultado de: "la pérdida de confianza en el futuro ya que está minado por el tiempo instantáneo y la proliferación de riesgos incalculables; la creencia que la vida social en el presente es profundamente decepcionante y que, en gran medida, los modos del pasado son preferibles a los del presente, hubo una Época Dorada" (Ibid.: 247). 
Así es como la confusión creada por un futuro incierto y unas percepciones turbias al respecto del tiempo conduce al reforzamiento del valor del pasado. Pero, más que ser una simple "vuelta al pasado" que generalizaría lo que Samuel (1996) llama la "cultura histórica" como si la masa estuviera "interesada" más que nunca en el pasado y la Historia, el patrimonio pretende traer el pasado al presente, donde el pasado es revivido por el presente y tiene que ser administrado y salvaguardado "para el futuro". Brevemente, la representación del pasado en el patrimonio no es algo a ser "conservado" y "protegido" sino más bien algo a ser "salvaguardado"; algo a salvar y guardar a través del tiempo (Micoud, 1996:122). En términos de Urry, el movimiento del patrimonio podría ser visto como una forma de 'estabilidad 'que resistiría el tiempo instantáneo y pretendería disminuir el paso del tiempo a la velocidad de la naturaleza"(2000: 157).

Otra forma de expresar esta relación "reconciliada" con el pasado es examinando la totalidad de la representación de la historia que también es reconsiderada y reconfigurada. Como explica Pomian (1998), en la era del "patrimonio" lo que cambia es la relación de la historia con la memoria (ver Halbwachs, 1960; Le Goff, 1988; Nora, 1997; Pomian, 1998).

La memoria es vida, siempre se refiere a grupos vivos, en constante moviemiento, abiertos a la dialéctica del recuerdo y la amnesia, inconsciente de las sucesivas deformaciones, vulnerable a todos los usos y manipulaciones, susceptible de largas permanencias latentes y repentinas revitalizaciones. La Historia es la reconstrucción, siempre problemática e incompleta de lo terminado. La memoria es un fenómeno siempre actual, una experiencia vinculante en el eterno presente; la Historia es una representación del pasado- Historia, porque está basada en operaciones intelectuales y seculares, requiere un análisis crítico y un discurso. Hace un siglo la Historia estaba circunscrita a salvar las fuentes de las "sociedades" con alfabeto; una cultura iletrada era cuestión etnológica. La Historia estaba relacionada a la memoria nacional al celebrar a los hombres prominentes y a los eventos relacionados con la idea del poder nacional como la invención de la tradición mencionada por Hobsbawm y Ranger (1983) o el "nacionalismo banal" de Biling (1995). En otras palabras, este "patrimonio nacional" estaba asociado con estos símbolos "inventados", "banales" de la nación para diferenciarse de "otros" "confirmando estatus, logro y distinción" (Urry, 2000: 148; ver también a McCrone, 1998; Smith, 1998). Como indica Urry, el patrimonio -al estar asociado con la nación, ha sido interrumpido por las movilidades y la "proliferación creciente de identidades subnacionales y transnacionales". Hoy asistimos a una revolución epistemológica destruyendo este antiguo dogma que solía ver a "la Historia como una ciencia, como una disciplina universitaria, visión del mundo y rama de la literatura" (Pomian, 1997: 905). Hoy, y más específicamente desde hace 30 años, asistimos a una multiplicación de sub-disciplinas que integran lo que Samuel (1994) denomina "historias ocultas" o "conocimiento no-oficial", lo que Urry (2000) llama "contestación vernacular al poder de las élites nacionales", y lo que la tradición francesa llama "memoria", hacia nuevas formas de "historias" relacionadas con diversas identidades y también nuevas representaciones de naciones. La Historia o las historias hoy representan "tradiciones populares y producciones artísticas, recuerdos orales, "know-hows" regionales y locales. De acuerdo con todos estos cambios, la idea de la Nación y su representación también han sido modificadas considerablemente. $Y$ también es el patrimonio quien ilustra estos cambios a través de la proliferación de museos y cambios en la museología donde un museo de arte, folklore y tradiciones populares, los museos, eco-museos, museos vivientes, parques temáticos y otros; nuevos tipos de "monumentos" protegidos, paisajes y parque nacionales protegidos, vestigios de antiguas industrias como fabricas, ferrocarriles, puertos, minas de carbón u cabañas abandonadas, etc.; junto con todos estos textos recientes que se han integrado a las historias orales de la memoria nacional de los grupos sociales marginales en nuevas formas de alcanzar una independencia como nación o neo-nacionalismos caracterizados por identidades múltiples (ver Urry 2000).

En pocas palabras, el patrimonio es una condición del Siglo XXI ya que refleja la fusión de la memoria y la Historia como nuevo sentido del pasado donde el pasado aún está conectado con el presente y dirigido hacia el futuro a "velocidad natural"; donde los historiadores se han involucrado en escribir libros para el público general y participan de programas conmemorativos, programas de radio y televisión; y donde la memoria y la historia se integran en un presente dinámico. El patrimonio es tam- 
bién visto como la nueva figura de la nación que no está limitada únicamente a los eventos políticos y militares y a los héroes desde "la alta cultura". El patrimonio lucha por crear la condición de nuevas nacionalidades. Es la fuerza la que da la estabilidad, los signos y símbolos reconocibles y las identidades suficientemente resistentes para un mundo acelerado.

Alexandra Arellano Facultad de Sociologia Universidad de Lancaster Lancaster, Reino Unido alexa_37@hotmail.com 


\section{BIBLIOGRAFÍA}

\author{
AUDRERIE, Dominique \\ 1997 La notion et la protection du patrimoine, \\ PUF, Paris. \\ AUDRERIE, D., Souchier, R., Vilar, L. \\ 1998 Le patrimoine mondial, PUF, Paris. \\ BASSAND, Michel, (dir) \\ 1991 Identité et développement régional, Berne, \\ Peter Lang.
}

Bromwich, James S.

1997 'Comparaison de politiques de marketing françaises et britanniques'en Publics etmusées, n.11-12: 103-139.

\section{CSERGO, Julia}

199 'La constitution de la spécialité gastronomique comme objet patrimonial en France, fin XVIIIe-Xxe siècle', en L'esprit des lieux, le patrimoine et la cité, PUG, Grenoble.

DEBORD, Guy

1996 La societe du spectacle, Gallimard, Paris.

\section{DE CERTEAU, Michel}

1978 L'Écriture de l'histoire, Gallimard, Paris.

DICKS, Bella

2000 Heritage, Place and Community, University of Wales Press, Cardiff.

DUMONT, Fernand

1995 L'avenir de la mémoire, Québec: Nuit Blanche Éditeur.

FAURE, Muriel

1999 'Un produit agricole affine en object culturel, les fromages de beaufort dans les Alpes du Nord', en TERRAIN 33 pp. 81-82.

FORTIN, Andrée et Hanvey FERNAND, (dirs)

1995 La nouvelle culture régionale, Québec, IQRC.
GRAHAM, B. J.

1994 'Heritage Conservation and Revisionist Nationalism in Ireland', en Ashworth, G. and Larkham, P. (eds) Building a New Heritage: Tourism culture and identity in the New Europe, Routledge, London.

GRANGE, Dominique J. and Poulot, Dominique 1997 L'esprit des lieux, le patrimoine et la cité, PUF, Grenoble.

\section{GENET-DELACROIX, Marie-Claude}

1997 'Etat et patrimoine sous la Ille République, De l'amateur au professionnel dans la gestion du patrimoine national', en Grange D. et Poulot, D, L'esprit des lieux, le patrimoine et la cité, PUF, Grenoble.

HARVEY, D

1989 The Condition of Postmodernity, Blackwell, Oxford.

HEWISON, Robert

1987 The Heritage Industry, London: Methuen.

1989 'Heritage: An Interpretation', en Heritage Interpretation, Volume 1, The natural and built environment,

1991 'Commerce and culture', en Enterprise and Heritage, Routledge.

HALBWACHS, Maurice

1950 Mémoires collectives, PUF, Paris.

HUYSSEN Andreas

1995 Twilight Memories, Marking Time in a Culture of Amnesia, New york: Routledge.

JUDD, Dennis R. and Fainstein, Susan S

1999 The Tourist City, Yale University Press.

LASH, Scott and Urry, John

1994 Economies of Signs \& Space, Sage

Publications. 


\section{LE GOFF, Jacques}

1988 Histoire et mémoire, Gallimard.

LEWIS, Peter

1991 Beamish, the North of England Open Air Museum, Museum Guide Book.

MACDONALD, S.

1997 Reimagining Culture, Histories, Identities and the Gaelic Renaissance, Berg.

MACDONALD, S.,

1997, 'A people's story: heritage, identity and authenticity', en C. Rojek and J. Urry (eds), Touring Cultures, London : Routledge.

MACLEAN, Fiona

1997 'Le passé est à vendre : réflexion sur le marketing des musées', en Publics et musées, n.11-12:15-37.

MALKOVICH, John

2001 'Captured by the Terrorist', en The Guardian, Friday Review, April $27^{\text {th }}$.

MACCRONE, David

1998 The Sociology of Nationalism, London: Routledge.

1995 Scotland - the Brand, the Making of Scottish Heritage, Edinburgh University Press.

MEETTHAM, Kevin

2001 Tourism in Global Society: Place, Culture, Consumption, PALGRAVE.

MICOUD, A.

1996 'Musée et patrimoine: deux types de rapport aux choses et au temps', Hermes, n. 20, CNRS Editons.

1994 'Le bien commun des patrimoines', en Patrimoine culturel, patrimoine naturel, La documentation Française.

MOREL, Alain

1995 'Politiques culturelles, production d'images et développement local', en J-P., Saez (dir) Identité et culture et temitoire, Paris, Descléede Brouwer.
NORA Pierre (dir)

1995 Les lieux de mémoire, Gallimard, Paris.

1997 Science et conscience du patrimoine, Editions du Patrimoine, Paris.

POMIAN, Krzysztof

1998 'De l'histoire, partie de la mémoire, à la mémoire, objet d'histoire' en Revue

Métaphysique et de Morale, n.1: 63-110.

1995 'L'heure des Annales', en Les Lieux de Mémoire, Gallimard, Paris.

RENAN, Ernest

1882 'What is a Nation?', reprinted en H.K. Bhabha (ed)

1990 Nation and Narration, London: Routledge.

RITZER, George and Liska, Allan

1997 Touring cultures, transformation of travel and theory, Routledge.

SAMUEL, Raphael

1994 Theatres of memory, London: Verso.

TUTTON, Richard

2001 Genes and Heritage, PhD. Dep of Sociology, Lancaster University (in preparation).

URRY, John

1990 The Tourist Gaze, Sage, London.

1996 'How societies remember the past', Theorising museums.

2000 Sociology Beyond Societies, mobilities for the twenty-first century, Routledge.

WALSH, Kevin

1992 The Representation of the Past, Routledge: London.

WRIGHT, Patrick

1985 On Living in an Old Country, Verso, London.

UNESCO

$2000 \quad$ www.unesco.org 